\title{
Numerical study of the role of mortar joints in the bond behavior of FRP-strengthened masonry
}

\author{
Bahman Ghiassi ${ }^{1}$, Daniel V. Oliveira ${ }^{2}$, Paulo B. Lourenço ${ }^{3}$, Giancarlo \\ Marcari $^{4}$
}

ISISE, University of Minho, Department of Civil Engineering, Guimarães, Portugal

\begin{abstract}
The performance of the interface between FRP and masonry is one of the key factors affecting the behavior of strengthened masonry elements. Therefore, a sound understanding of the interface behavior is crucial at the design stage. In this paper, the effect of mortar joints in the bond behavior of FRPstrengthened masonry prisms is investigated through numerical modeling. The numerical simulation is performed by adopting a nonlinear three-dimensional micro-modeling approach. Different smeared crack models are considered, and the results are compared in terms of local stress and strain distributions, global force-slip response, and cracking pattern. The accuracy of the FE predictions have been assessed by comparing the results with test data and it was found that three-dimensional FE modeling combined with a rotating smeared crack approach gives the best results, both at local and global levels. Finally, the numerical results obtained considering the presence of mortar joints with different mechanical properties are presented and critically discussed.
\end{abstract}

Keywords: A. Polymer-matrix composites; Masonry; B. Debonding; C. Numerical analysis.

${ }^{1} \mathrm{PhD}$ Student, ISISE, University of Minho, Department of Civil Engineering, Azurém, 4800-058 Guimarães, Portugal. Phone: +351 253510 499, fax: +351 253510 217, Email: bahmanghiassi@civil.uminho.pt.

${ }^{2}$ Associate Professor, ISISE, University of Minho, Department of Civil Engineering, Azurém, 4800-058 Guimarães, Portugal. Phone: +351 253510 247, fax: +351 253510

217, E-mail: danvco@civil.uminho.pt.

${ }^{3}$ Professor, ISISE, University of Minho, Department of Civil Engineering, Azurém, 4800-058 Guimarães, Portugal. Phone: +351 253510 209, fax: +351 253510 217, Email: pbl@civil.uminho.pt.

${ }^{4}$ Assistant Researcher, ISISE, University of Minho, Department of Civil Engineering, Azurém, 4800-058 Guimarães, Portugal. Phone: +351 253510 498, fax: +351 253510 217, E-mail: marcarigia@civil.uminho.pt. 


\section{Introduction}

The performance of masonry elements externally strengthened with fiber reinforced polymers (FRPs) depends on the bond behavior between the composite material and the masonry substrate. Failure of the bond interface may lead to deterioration of composite action or premature debonding. Therefore, a sound understanding of the interface behavior is crucial for design and assessment purposes. Considerable research has been directed over the past decade for studying of bond behavior in FRP-strengthened masonry elements, experimentally [1-7] and numerically [8-11]. However, few studies have considered the presence of mortar joints along the bonded length, see e.g. [2-5, 9$11]$, and this issue still remains unknown.

Within the finite element studies, due to the difficulties of adopting a micro model where units, mortar, epoxy, and FRP have to be modeled separately, usually the bond behavior is modeled by using interface elements in a two or three dimensional space, see e.g. [8]. However, the adoption of a three dimensional micro model-based approach able to follow crack propagation and failure is crucial to understand the fundamental mechanics of FRP-masonry interfacial behavior. The numerical studies about interfacial behavior are mostly devoted to micro-modeling of externally bonded FRP-strengthened concrete elements, and only few investigations on masonry components strengthened with composite materials have been carried out. Usually, a two dimensional modeling approach is used, e.g. [9, 12-13], and only a few three dimensional analyses can be found $[9-10,14]$. The three dimensional approach adopted in [14] assumed linear elastic behavior for modeling FRP-strengthened concrete elements. However, probably the only three-dimensional nonlinear modeling approach used for externally bonded FRPstrengthened masonry is presented by Fedele and Milani [9-10]. In this case, a damage model was used for representing the failure and damage propagation in masonry prisms. 
The phenomenological approaches for numerical modeling above can be clustered into two main categories. In the first approach, the bond behavior is modeled using a zero thickness interface element between FRP and substrate. Within this approach, the nonlinearities are concentrated at the FRP-substrate interface, while FRP and substrate are characterized by an elastic behavior. This approach is very attractive since it can potentially capture the critical aspects related to interfacial mechanics and bond failure initiation and propagation. The second approach consists of the cracking and failure of all constituents according to a meso-scale model. In this approach FRP, epoxy, and the substrate are modeled separately with the assumption of perfect adhesion between different layers. An advantage of this approach is that the complex stress conditions and interaction of cracks observed in real structural systems can be simulated. Moreover, the strain and stress evolution in all the material constituents can be followed and simplified bond-slip models can be derived based on the results obtained from this approach.

Another possibility would be the use of micro-mechanical models, where all particularities, as the penetration of the resin into the substrate, can be modeled. This approach has not been used before, is time consuming and requires data hardly available, such as the depth of resin penetration in the substrate and its variation along the bonded area. The adoption of a three-dimensional meso-scale modeling approach seems adequate to investigate the bond behavior in detail and has only been attempted before in [9-10]. The aim of this paper is to investigate the effect of joint quality on the bond behavior of FRP-strengthened masonry elements. Moreover, the three dimensional nature of the debonding problem and interfacial stress distributions are discussed. A fully three dimensional numerical analysis for modeling the nonlinear bond behavior in FRP-strengthened masonry elements is used together with a smeared crack modeling approach. It is noted that the most used isotropic or anisotropic damage models, and 
rotating or fixed crack models, provide reasonably different responses after the onset of inelastic behavior and some guidance is useful and necessary. Here, different cracking models and mesh sizes were used to discuss mesh sensitivity and convergence of the results to available experimental data. The accuracy of the models is assessed by comparing the overall (force-slip curves) and local (strain distributions along the bonded length) responses with experimental results, allowing a sound selection of the material models to be used in advanced simulations.

Three-dimensional aspects of bond behavior such as debonding and crack propagation, failure surface, and stress distributions, which are usually neglected in two-dimensional models, are also investigated. Finally, the presence of mortar joints on the bond behavior is studied. In this regard, mortar joints with different material properties representing poor quality and high quality mortars are considered, and their effects on the response of the strengthened element are critically discussed. A comprehensive parametric study is also performed on FRP axial stiffness and width, and the effectiveness of mortar joints in each case is investigated.

\section{FE model}

\subsection{Outline}

A three dimensional nonlinear FE model has been adopted for modeling the typical single-lap shear bond tests on FRP-strengthened masonry bricks, see Fig.1. Due to the symmetry of the model configuration, only half of the structure was modeled. The boundary conditions were applied as given below in the reference experimental tests, which are described next. A monotonic incremental displacement was applied at the end of the FRP sheet in order to simulate the pulling force. 
The analysis was carried out in the FE code DIANA [15]. The adopted mesh includes twenty-node solid elements (denoted by $\mathrm{CHX60)}$ to model the brick and epoxy layer, and eight-node shell elements (denoted by CQ40F) for the FRP strip. Perfect bond was assumed between the FRP strip and the epoxy layer, and between the epoxy layer and brick.

\subsection{Material models}

A smeared crack model was used for modeling the debonding progress and crack propagation in masonry, while linear elastic behavior was assumed for the FRP and the adhesive layer. Since failure occurs usually in the upper layer of the brick, this assumption seems reasonable.

Crack models in advanced finite element software packages are usually based on the smeared crack or discrete crack modeling approaches [16]. Since smeared crack modeling approaches do not require remeshing of the FE model after occurrence of cracks or a priori definition of possible location of cracks, they have been widely used in FE modeling. The FE code DIANA includes the following smeared crack modeling approaches: total strain fixed crack model (FCM), multi-directional fixed crack model (MFCM), and total strain rotating crack model (RCM).

In the fixed smeared cracking approach, the orientation of crack is fixed after appearance of the first crack. Consequently, shear stresses develop in the crack plane with the change in direction of principal stresses during the analysis. A reduction in severity of the mesh bias problem, a better representation of strut and tie mechanisms in the substrate, and the definition of the parameters from well-established standard tests are the advantages of this approach, while the shear stress locking problem can be noted as the main disadvantage [16-17]. The shear stiffness after cracking is given by the shear retention factor, which can be a constant (low) value between 0 and 1 , or a 
vanishing value with crack opening. Here, constant values equal to 0.01 and 0.1 were adopted, meaning that no shear softening behavior is possible. Different solutions, such as mesh refinement or using negative values for the shear retention factor, have been proposed for solving the problem of shear locking, but following the crack development in delamination problems remains impossible using this method [16].

Multi-directional fixed crack or rotating crack models seem more suitable for debonding problems, in which high shear stresses develop. In the MFCM, if the angle between the principal tensile stress and crack orientation becomes larger than a specified value, $\theta$, new orthogonal cracks form in the direction of the principal stresses and the old cracks become deactivated. In the special case where $\theta$ is equal to zero, the crack direction is always perpendicular to the principal stress direction, providing a rotating crack approach (RCM).

The ability of fixed and rotating smeared crack modeling approaches in simulating the bond behavior in FRP-strengthened masonry elements is investigated in section 3.3. Here, the behavior of the brick is modeled using a parabolic hardening/softening model in compression and an exponential softening model in tension. The reduction of compressive strength due to lateral cracking is also considered using the model proposed by Vecchio and Collins [17].

\section{Validation of the FE model}

\subsection{Reference experimental results}

A wide experimental campaign aimed at investigating the bond behavior of FRP-bricks through single-lap shear bond tests has been carried out at the University of Minho, using different composite materials, see also [18]. The results obtained for six CFRPbrick specimens are used in this study for the validation of the FE model. 
The CFRP strips have a width of $50 \mathrm{~mm}$ and were applied on masonry bricks following the wet layup procedure. The bonded length of the strips was equal to $160 \mathrm{~mm}$ with a 40 mm unbounded part at the loaded end, see Fig.2. Three strain gauges were glued on the bonded area of the strip and one strain gauge was glued on the unbonded area.

Masonry clay bricks with dimensions $250 \times 120 \times 55 \mathrm{~mm}^{3}$ were used, with a mean compressive strength of $19.8 \mathrm{MPa}(\mathrm{CoV}=2.5 \%)$, a tensile strength of $2 \mathrm{MPa}(\mathrm{CoV}=4 \%)$, and a Young's Modulus equal to $5580 \mathrm{MPa}(\mathrm{CoV}=5.2 \%)$. Here, $\mathrm{CoV}$ is the coefficient of variation. The fracture energy of the brick has been selected equal to $12.5 \mathrm{~N} / \mathrm{mm}$ for compression, $0.19 \mathrm{~N} / \mathrm{mm}$ in for tension, and Poisson's ratio equal to 0.2 based on the available data in the literature, e.g. $[19,20]$. The mechanical characteristics of the composite, obtained from experimental tests, are equal to $202 \mathrm{GPa}$ for the modulus of elasticity, $E_{f}, 2530 \mathrm{MPa}$ for the tensile strength, $f_{t}, 1.16 \%$ for the ultimate deformation, $\varepsilon_{\max }$, and $0.17 \mathrm{~mm}$ for the composite thickness, $t_{f}$. The experimental results are next validated in terms of force-slip diagrams and strain distribution along the FRP.

\subsection{Mesh dependency of the model}

Three different mesh sizes were used, Mesh 1 (coarsest mesh) to Mesh 3 (finer mesh), in order to assess convergence of the results. The minimum element size, the total number of elements and the total number of nodes for each mesh are shown in Table 1.

Fig.3 presents the obtained force-slip curves with different mesh sizes, considering the usual regularization of the fracture energy according to the element size [21]. Mesh 2 and Mesh 3 produced similar results, while the results predicted with the coarsest mesh (Mesh 1) are slightly different and indicate that the mesh is not sufficiently refined. As for the local behavior, the strain distributions along the bonded length are shown in Fig.4 for two load levels of $\mathrm{P} / \mathrm{P}_{\mathrm{u}}=0.2$ and $\mathrm{P} / \mathrm{P}_{\mathrm{u}}=1.0$. In case of the $\mathrm{P} / \mathrm{P}_{\mathrm{u}}=0.2$, the strain 
(and stress, as linear elastic behavior is assumed for the FRP) distributions predicted with different mesh sizes are almost identical, while in $\mathrm{P} / \mathrm{P}_{\mathrm{u}}=1.0$, the results predicted by Mesh 1 are different from other mesh types.

The normal and shear stress distributions in the adhesive-brick interface and the adhesive mid-section have also been investigated for different mesh sizes at the ultimate load level, see Fig.5. The stresses have been obtained at the nodes by the usual averaging procedures. In the adhesive mid-section, the normal stresses in Mesh 1 are again slightly different from the stresses from other mesh types near the loaded end. By moving towards the free end the results converge for all types of meshes. The shear stresses are almost identical for all mesh sizes with a slight difference of Mesh 1 and some fluctuations in Mesh 2 near the loaded end. The stress distribution coincides in all meshes after a short distance from the loaded end, similarly to the strain distributions. In the adhesive-brick interface a similar difference exists near the loaded end between the results obtained from Mesh 1 and the results obtained from Mesh 2 and Mesh 3. Moreover, the stresses increase with mesh refinement at the loaded end due to the existence of stress singularities, as expected and discussed e.g. in [22-24].

The comparison made indicates that Mesh 2 and Mesh 3 are fine enough for obtaining reasonable results. Therefore, the results presented hereafter are obtained using the model with Mesh 2.

\subsection{Material crack models}

The force-slip curves obtained using different crack models are shown in Fig.6 in comparison with the envelope of the experimental curves. Since the effect of using different softening models has been found to be negligible [12], an exponential softening model is adopted in this study for all cracking models. In the fixed smeared crack model (FCM), constant shear retention factors of $\beta=0.1$ and $\beta=0.01$ are used. It 
can be observed that the results predicted by the rotating crack model (RCM) is in reasonable agreement with the experimental results, while the other crack models do not produce satisfactory results. The shear stress locking problem in the fixed smeared crack models has resulted in increment of the shear stresses even after evolution of cracks.

A comparison of experimental and numerical results in terms of strain distribution along the FRP sheets have also been made for two different load levels of $\mathrm{P} / \mathrm{P}_{\mathrm{u}}=0.2$ and $\mathrm{P} / \mathrm{P}_{\mathrm{u}}=1.0$, see Fig.7. For $\mathrm{P} / \mathrm{P}_{\mathrm{u}}=0.2$, the strain distributions are predicted accurately in all cracking models, as the results are mostly elastic. On the other hand, for $\mathrm{P} / \mathrm{P}_{\mathrm{u}}=1.0$ only the results obtained from RCM and FCM $(\beta=0.1)$ are in relatively good agreement with experimental results.

In general, the results show that RCM can provide better results than FCM. Therefore, this crack modeling approach has been selected in this study for numerical simulation of the debonding phenomenon.

\subsection{Three dimensional effects}

The normal and shear stresses $\left(\right.$ at $\left.\mathrm{P} / \mathrm{P}_{\mathrm{u}}=1.0\right)$ along the edge and middle (center line) of the FRP sheet are shown in Fig.8 and Fig.9 at mid-height-adhesive and brick-adhesive sections, respectively. It can be seen that the stress distribution is different along the FRP width, especially in the case of shear stresses (Fig.8 (b) and Fig.9 (b)), due to the boundary effect. In this case, at the mid-height-adhesive section the maximum normal compressive stress is $6.3 \mathrm{MPa}$ along the edge of the FRP sheet, and 5.8 $\mathrm{MPa}$ along the middle. On the other hand, the maximum tensile stress along the FRP edge is $3.6 \mathrm{MPa}$ and 4.5 MPa along the FRP middle. In case of the maximum shear stress, the difference is rather large in absolute value up to $80 \mathrm{~mm}$ from the loaded end. Along the FRP edge the maximum (absolute) shear stress is $10.8 \mathrm{MPa}$, while along the middle a value about 
3.6 times lower was obtained (3.0 MPa). At the brick-adhesive section, the maximum normal compressive stress is $16.2 \mathrm{MPa}$ along the edge of the FRP sheet, while it is 14.5 $\mathrm{MPa}$ along the FRP middle. The maximum tensile stress along the FRP edge is 2.8 $\mathrm{MPa}$, while it is $3.4 \mathrm{MPa}$ along the FRP middle. The maximum (absolute) shear stress approaches $13.5 \mathrm{MPa}$ and $8.13 \mathrm{MPa}$ along the FRP edge and middle, respectively. It can be observed that a considerable difference exists between the shear stresses along the FRP edge and middle. This difference, also reported for FRP-strengthened concrete elements in [14], shows the three-dimensional nature of the debonding problem which is neglected in conventional 2D modeling approaches. Moreover, the significant difference of compressive and tensile stresses between mid-height-adhesive and brickadhesive sections shows the existence of relevant bending stresses near the loaded end, which are larger at the edge of the FRP sheet.

The numerical distribution of cracks inside the specimens is plotted in Fig.10 for the case of $\mathrm{P} / \mathrm{P}_{\mathrm{u}}=0.8$. It can be seen that failure occurred involving a thin layer of the brick, whereas the remaining brick exhibits no damage. This result is in very good agreement with the experimental results. Another phenomenon observed in the experimental tests was that the debonded area was larger than the FRP bonded area, indicating the propagation of cracks along the FRP width and length. The adopted model was able to capture this aspect also. As shown in Fig.10 (b), the cracks propagate out of the bonded area in the brick surface.

\section{Role of mortar joints in the bond behavior}

The effect of the presence of mortar joints on the debonding behavior of FRPstrengthened masonry elements is investigated in this section. It has been widely accepted in the literature that FE models, when validated with experimental results, can be used effectively to simulate similar problems and avoid performing extensive 
experimental tests. The debonding problem in masonry prisms is a very complex phenomenon, and the validated FE model is used to gain insight of the phenomenon, as a laboratory simulation. For this purpose, two mortar joints with $15 \mathrm{~mm}$ thickness are added to the brick model described in the previous section, see Fig.11. The total strain rotating crack model was used again for modeling the cracking behavior of bricks and mortar joints. The material properties used for the FRP sheet and bricks were kept unchanged. Two different material properties were used for the mortar joints, representing high (M1) and low quality (M2) mortars, respectively, with mechanical characteristics summarized in Table 2. Different FRP axial stiffness $\left(E_{\mathrm{f}} t_{\mathrm{f}}\right)$ and width (the ratio of FRP width to brick width, $\mathrm{r}=b_{\mathrm{f}} / b$ ) have been considered in the numerical analysis to understand the effect of the different parameters. The reference FRP axial stiffness, $E_{\mathrm{f}} t_{\mathrm{f}}$, and width ratio, $r$, are equal to $34.3 \mathrm{kN} / \mathrm{mm}$ and 0.42 , respectively.

\subsection{Global behavior}

The numerical force-slip curves obtained for mortars M1 and M2 are shown in Fig.12 together with the model without mortar joints (reference model) for different FRP axial stiffness. It can be observed that the bond strength tends to decrease when the mortar becomes weaker, as expected. Moreover, the decrease in the bond strength increases for higher FRP axial stiffness. For $E_{\mathrm{f}} t_{\mathrm{f}}=34.3 \mathrm{kN} / \mathrm{mm}$, the maximum debonding force in the model without mortar is $7.5 \mathrm{kN}$, while it is $7.0 \mathrm{kN}(-6 \%)$ for mortar M1 (with high quality) and $5.2 \mathrm{kN}(-30 \%)$ for mortar M2 (with poor quality). For $E_{\mathrm{f}} t_{\mathrm{f}}=20.2 \mathrm{kN} / \mathrm{mm}$, the maximum debonding force in the model without mortar is $5.9 \mathrm{kN}$, while it is $5.5 \mathrm{kN}$ $(-6.14 \%)$ for mortar M1 and $5.2 \mathrm{kN}(-10.9 \%)$ for mortar M2. For $E_{\mathrm{f}} \mathrm{t}_{\mathrm{f}}=8.4 \mathrm{kN} / \mathrm{mm}$, the maximum debonding force in the model without mortar is $4.2 \mathrm{kN}$, while it is $3.9 \mathrm{kN}$ ($5.7 \%$ ) for mortar M1 and $3.8 \mathrm{kN}(-9 \%)$ for mortar M2. The variation of bond strength with FRP axial stiffness is shown in Fig.13. The effect of high quality mortar in the 
bond strength seems negligible for the cases studied here. On the other hand, the bond strength decreased significantly in the models with poor quality mortar for higher values of FRP axial stiffness.

The effect of mortar joint quality on the bond strength has also been investigated for different $r$ (FRP width to brick width) ratios. Three different $r$ ratios equal to 0.42, 0.7, and 0.9 were considered. The modeling strategy was to keep the brick width constant $(120 \mathrm{~mm})$ and increase the FRP width according to the corresponding $r$ ratio. The bond strength variation for different $r$ ratios and mortar quality is shown in Fig.14. The bond strength increases with the FRP width. Again, the mortar quality affects the bond strength, especially for higher FRP axial stiffness.

It is expected that the decrease in bond strength in the models with poor quality mortar can be regained by increasing the bond length. This has been investigated by increasing the bond length in the M2 models from $160 \mathrm{~mm}$ to $190 \mathrm{~mm}$. The $30 \mathrm{~mm}$ increase in bond length is equal to the total thickness of mortar joints. The results are shown in Fig.15 in terms of force-slip curves. It can be seen that the original bond strength of the model without mortar has been regained, which is a much relevant result for practical applications.

\subsection{Local stress and strain distributions}

Investigating the local stress and strain distributions is crucial for the understanding of the interfacial behavior obtained in numerical models with a bond-slip law. Moreover, the three dimensional nature of debonding can be investigated from the analysis of local stress and strain distributions.

The normal and shear stress distributions along the bonded length in the brick-adhesive interface are shown in Fig.16 for $E_{\mathrm{f}} t_{\mathrm{f}}=34.3 \mathrm{kN} / \mathrm{mm}$ and $\mathrm{P} / \mathrm{P}_{\mathrm{u}}=1.0$. The normal stress distribution in model M1 is similar to the reference model, with slightly higher stress 
values near the loaded end. The normal stresses of M2 exhibit fluctuations near the loaded end and the mortar joints. The shear stress distributions of the reference model and of model M1 have similar behavior, with only small differences near the loaded end. On the other hand, the shear stress distribution in model M2 shows sudden drops in correspondence of the mortar joints, due to the formation of large cracks. Moreover, a different distribution of stresses is observed between the FRP edge and middle in both M1 and M2 prisms, see Fig.17. This difference, being an evidence of three dimensional nature of debonding problem, significantly increases with the FRP axial stiffness. However, for higher values of $r$ ratio the difference between stress distributions along the FRP edge and middle decreases.

\subsection{Local FE bond-slip behavior}

The local bond-slip curves along the bonded length can be obtained from FE results. As an example, the bond-slip behavior at four different sections is presented in Fig.18 for the reference model, $E_{\mathrm{f}} t_{\mathrm{f}}=34.3 \mathrm{kN} / \mathrm{mm}$ and $r=0.42$. The sections are selected in such a way to understand the differences of local bond-slip behavior in the brick-adhesive and mortar-adhesive interfaces in different positions.

The numerical bond-slip curves obtained at sections 1 (first brick) and 2 (first mortar joint) are characterized by an almost bilinear trend with ascending and descending branches. The descending branch starts when the substrate material reaches its softening behavior due to the occurrence of large cracks. Such behavior is common in M1 and M2 models. The bond-slip curves evaluated at points 3 and 4 are characterized by an ascending branch with low slip values showing that these sections are still in their linear range of behavior. In the M2 model, brick and mortar in sections 1 and 2 have reached the maximum slip and the FRP has completely debonded in these sections. The bond strength in the brick-adhesive section, section 1, is 1.7 MPa. However, the bond strength 
in the mortar-adhesive section, section 2, is $1.5 \mathrm{MPa}$ in model with mortar M1 and 0.5 MPa in model with mortar M2.

It can be seen that the response of the brick-adhesive and mortar-adhesive in terms of bond-slip curves can be different, especially when poor mortar quality is considered. This aspect requires further consideration when interface elements or bond-slip models are used. Possible solutions are to use an average bond-slip model or different bond-slip models for FRP-brick and FRP-mortar interfaces.

\subsection{Crack distribution}

As discussed before, the failure mechanism in the experimental tests using FRP-brick specimens involved only the external layer of the bricks. The crack patterns obtained at the peak load for the models with mortar joints are now illustrated in Fig.19 for two $r$ ratios of 0.42 and 0.9 . In case of $r$ equal to 0.42 and mortar type M1, the cracks propagate slightly inside the masonry prism, while in model M2 they propagated in depth within the specimens. The crack propagation occurs especially near the mortar joints, as it was expected from the strain and stress distributions described. However, in the model with $r$ equal to 0.9 the cracks propagated deeply inside the brick and mortar in both models, being deeper in model M2.

\section{Conclusions}

A fully three dimensional nonlinear model for investigating the bond behavior in FRPstrengthened masonry elements was presented. Different smeared cracking models and mesh sizes were used to obtain numerical convergence and results that compare well to available experimental data. It was found that the rotating smeared crack model is suitable for predicting debonding. The accuracy of the model was verified by comparing the overall (force-slip curves) and local (strain distributions along the bonded length) 
response of the model with experimental results. The crack distribution and the failure mode were found in good agreement with the experimental results.

It has been shown that failure surfaces and crack propagation have a three dimensional nature. In particular, the interfacial stress distributions are different along the FRP edge. The effect of the presence of mortar joints on the bond behavior was studied by modeling two mortar joints along the bonded length. Different material properties were used for the mortar joints representing poor and high quality mortars. The effects of mortar joints were investigated on the global and local response of the strengthened elements. It was observed that a poor quality mortar may lead to a significant reduction of the bond strength. This effect reduces with decreasing FRP axial stiffness. It was also shown that a solution to regain the original bond strength is to increase the effective bond length in the presence of poor quality mortar. Moreover, the difference of stress distributions between the FRP edge and FRP middle sections was larger in the model with poor quality mortar. The effective bond length was observed to increase significantly in the model with poor quality mortar. The local bond-slip curves obtained from the FE results showed that the bond behavior is different in brick-adhesive and mortar-adhesive interface, with much larger slip in the model with poor mortar quality. A solution to this problem for macro-modeling approaches is to use an average bondslip model or different bond-slip models in brick-adhesive and mortar-adhesive interfaces.

\section{Acknowledgements}

This work was partly funded by project FP7-ENV-2009-1-244123-NIKER of the 7th Framework Program of the European Commission, which is gratefully acknowledged. The first author also acknowledges the financial support of the Portuguese Science 
Foundation (Fundação de Ciência e Tecnologia, FCT), through grant SFRH/BD/80697/2011.

\section{References}

[1] Faella C, Camorani G, Martinelli E, Paciello SO, Perri F. Bond behavior of FRP strips glued on masonry: Experimental investigation and empirical formulation. Constr Build Mater 2012; 31:353-63.

[2] Kashyap J, Willis CR, Griffith MC, Ingham JM, Masia MJ. Debonding resistance of FRP-to-clay brick masonry joints. Eng Struct 2012; 41:186-98.

[3] Capozucca R. Effects of mortar layers in the delamination of GFRP bonded to historic masonry. Compos B 2012; http://dx.doi.org/10.1016/j.compositesb.2012.02.012.

[4] Carrara P, Ferretti D, Freddi F. Debonding behavior of ancient masonry elements strengthened with CFRP sheets. Compos: Part B 2012; http://dx.doi.org/10.1016/j.compositesb.2012.04.029

[5] Oliveira DV, Basilio I, Lourenço PB. Experimental bond behavior of FRP sheets glued on brick masonry. J Compos Constr 2010; 14(3):312-323.

[6] Capozucca R. Experimental FRP/SRP- historic masonry delamination. Compos Struct 2010; 92(4):891-903.

[7] Garbin E, Panizza M, Valluzzi MR. Experimental assessment of bond behavior of fiber-reinforced polymers on brick masonry. Struct Eng Int 2010; 20(4):392-99.

[8] Grande E, Imbimbo M, Sacco E. Bond behavior of CFRP laminates glued on clay bricks: Experimental and numerical study. Compos: Part B 2011; 42(2):330-40.

[9] Fedele R, Milani G. A numerical insight into the response of masonry reinforced by FRP strips. The case of perfect adhesion. Compos Struct 2010; 92(10):234557. 
[10] Fedele R, Milani G. Three-dimensional effects induced by FRP-from-masonry delamination. Compos Struct 2011; 93(7):1819-31.

[11] Fedele R, Milani G. Assessment of bonding stresses between FRP sheets and masonry pillars during delamination tests. Compos: Part B 2012; 43(4):19992011.

[12] Lu XZ, Ye LP, Teng JG, Jiang JJ. Meso-scale finite element model for FRP sheets/plates bonded to concrete. Eng Struct 2005; 27(4):564-75.

[13] Coronado C, Lopez M. Damage approach for the prediction of debonding failure on concrete elements strengthened with FRP. ASCE J Compos Constr 2007; 11(4):391-400.

[14] Chen JF, Pan JW. Three dimensional stress distribution in FRP-to-concrete bond test specimens. Constr Build Mater 2006; 20(1-2):46-58.

[15] DIANA. Displacement analyzer software. V. 9.4.4, TNO Diana BV, Delft, The Netherlands, 2012.

[16] Rots J, Blaauwendraad J. Crack models for concrete: discrete or smeared? Fixed, multidirectional or rotating. Heron 1989; 34(1):1-59.

[17] Vecchio FJ, Collins MP. Compression response of cracked reinforced concrete. J Struct Eng 1993; 119(12):3590-610.

[18] Valluzzi, MR, Oliveira, DV, et al. Round robin tests on bond investigation of composite-to-masonry unit under shear actions. Mater Struct 2012 (accepted for publication, DOI 10.1617/s11527-012-9883-5).

[19] Lourenço PB, Fernandes F, Castro F. Handmade clay bricks: Chemical, physical and mechanical properties. Inter J Arch Herit 2010; 4(1):38-58.

[20] Lourenço PB. Recent advances in masonry structures: Micromodeling and homogenization in: Multiscale Modeling in Solid Mechanics: Computational 
Approaches, Eds. U. Galvanetto, M.H. Ferri Aliabadi, Imperial College Press 2009: 251-294.

[21] Bažant ZP, Oh BH. Crack band theory for fracture of concrete. Mater and Struct $1983 ; 16(3): 155-177$.

[22] Lu XZ, Jiang JJ, Teng JG, Ye LP. Finite element simulation of debonding in FRPto-concrete bonded joints. Constr Build Mater 2006; 20(6):412-24.

[23] Teng J, Zhang J, Smith S. Interfacial stresses in reinforced concrete beams bonded with a soffit plate: a finite element study. Constr Build Mater 2002; 16(1):1-14.

[24] Hein V, Erdogan F. Stress singularities in a two-material wedge. Int J Fract Mech 1971; 7(3):317-30. 


\section{List of tables}

Table 1. Adopted mesh types.

Table 2. Mechanical properties of the mortar types.

\section{List of figures}

Fig.1. Adopted finite element model: (a) elevation; (b) top view (x-y plane).

Fig.2. Geometry of the reference FRP-masonry brick specimens.

Fig.3. Force-slip curves obtained for different mesh sizes.

Fig.4. Effect of mesh size on strain distributions in the FRP sheet. Note that the results for all meshes coincide for $\mathrm{P} / \mathrm{Pu}=0.2$ and the results for Mesh and Mesh 3 coincide for Mesh 2 and Mesh 3.

Fig.5. Effect of mesh size on stress distributions at the ultimate load level, $\mathrm{P} / \mathrm{P}_{\mathrm{u}}=1.0$ : (a) adhesive mid-section; (b) adhesive-brick interface.

Fig.6. Force-slip curves obtained for different crack models.

Fig.7. Strain distributions along the FRP sheet for different crack models: (a) $\mathrm{P} / \mathrm{P}_{\mathrm{u}}=0.2$; (b) $\mathrm{P} / \mathrm{P}_{\mathrm{u}}=1.0$.

Fig.8. Stress distributions along the bonded length at mid-height-adhesive section at $\mathrm{P} / \mathrm{P}_{\mathrm{u}}=1.0$ : (a) normal stress; (b) shear stress.

Fig.9. Stress distributions along the bonded length at brick-adhesive section at the ultimate load level, $\mathrm{P} / \mathrm{P}_{\mathrm{u}}=1.0$ : (a) normal stress; (b) shear stress.

Fig.10. Numerical crack pattern of the FRP and brick specimen modeled in $3 \mathrm{D}$ at $\mathrm{P} / \mathrm{P}_{\mathrm{u}}=0.8$ : (a) side view; (b) top view. 
Fig.11. Adopted finite element model for FRP-strengthened masonry prism.

Fig.12. Force-slip curves for different mortar types and FRP axial stiffness for $r=0.42$ :

(a) $E_{\mathrm{f}} t_{\mathrm{f}}=34.3 \mathrm{kN} / \mathrm{mm}$; (b) $E_{\mathrm{f}} t_{\mathrm{f}}=20.2 \mathrm{kN} / \mathrm{mm}$; (c) $E_{\mathrm{f}} t_{\mathrm{f}}=8.4 \mathrm{kN} / \mathrm{mm}$.

Fig.13. Variation of bond strength with FRP axial stiffness for $r=0.42$.

Fig.14. Effect of FRP width ratio, $r$, on the bond strength: (a) $E_{\mathrm{f}} \mathrm{t}_{\mathrm{f}}=34.3 \mathrm{kN} / \mathrm{mm}$; (b) $E_{\mathrm{f}} t_{\mathrm{f}}$ $=8.4 \mathrm{kN} / \mathrm{mm}$.

Fig.15. Effect of increase in the bond length in model M2 for $r=0.42$ : (a) $E_{\mathrm{f}} t_{\mathrm{f}}=34.3$ $\mathrm{kN} / \mathrm{mm}$; (b) $E_{\mathrm{f}} \mathrm{t}_{\mathrm{f}}=20.2 \mathrm{kN} / \mathrm{mm}$; (c) $E_{\mathrm{f}} \mathrm{t}_{\mathrm{f}}=8.4 \mathrm{kN} / \mathrm{mm}$.

Fig.16. Stress distributions along the bonded length at $\mathrm{P} / \mathrm{P}_{\mathrm{u}}=1.0$ for $E_{\mathrm{f}} t_{\mathrm{f}}=34.3 \mathrm{kN} / \mathrm{mm}$ and $r=0.42$ : (a) normal stress; (b) shear stress.

Fig.17. Shear stress distributions along the bonded length at the interface for $P / P_{u}=1.0$ : (a) prism with mortar M1; (b) prism with mortar M2.

Fig.18. FE local bond-slip curves: (a) sections under investigation; (b) model with mortar M1; (c) model with mortar M2.

Fig.19. Crack distributions for $E_{\mathrm{f}} t_{\mathrm{f}}=34.3 \mathrm{kN} / \mathrm{mm}$ and different $r$ ratios: (a) $r=0.42$; (b) $r=0.9$. 
Table 1. Adopted mesh types.

\begin{tabular}{llll}
\hline $\begin{array}{l}\text { Mesh } \\
\text { type }\end{array}$ & $\begin{array}{l}\text { Minimum } \\
\text { element size } \\
(\mathrm{mm})\end{array}$ & $\begin{array}{l}\text { Total no. } \\
\text { of elements }\end{array}$ & $\begin{array}{l}\text { Total no. } \\
\text { of nodes }\end{array}$ \\
\hline Mesh 1 & 1 & 2700 & 12271 \\
\hline Mesh 2 & 0.5 & 13900 & 59925 \\
\hline Mesh 3 & 0.25 & 106800 & 443849 \\
\hline
\end{tabular}


Table 2. Mechanical properties of the mortar types.

\begin{tabular}{ccccccc} 
Mortar type & $\begin{array}{c}E \\
(\mathrm{GPa})\end{array}$ & $v$ & $\begin{array}{c}f_{\mathrm{c}} \\
(\mathrm{MPa})\end{array}$ & $\begin{array}{c}G_{f c} \\
(\mathrm{~N} / \mathrm{mm})\end{array}$ & $\begin{array}{c}f_{\mathrm{t}} \\
(\mathrm{MPa})\end{array}$ & $\begin{array}{c}G_{f t} \\
(\mathrm{~N} / \mathrm{mm})\end{array}$ \\
\hline $\mathrm{M} 1$ & 8 & 0.1 & 10 & 2.7 & 1.0 & 0.035 \\
\hline $\mathrm{M} 2$ & 2 & 0.1 & 3 & 1.8 & 0.25 & 0.018 \\
\hline
\end{tabular}




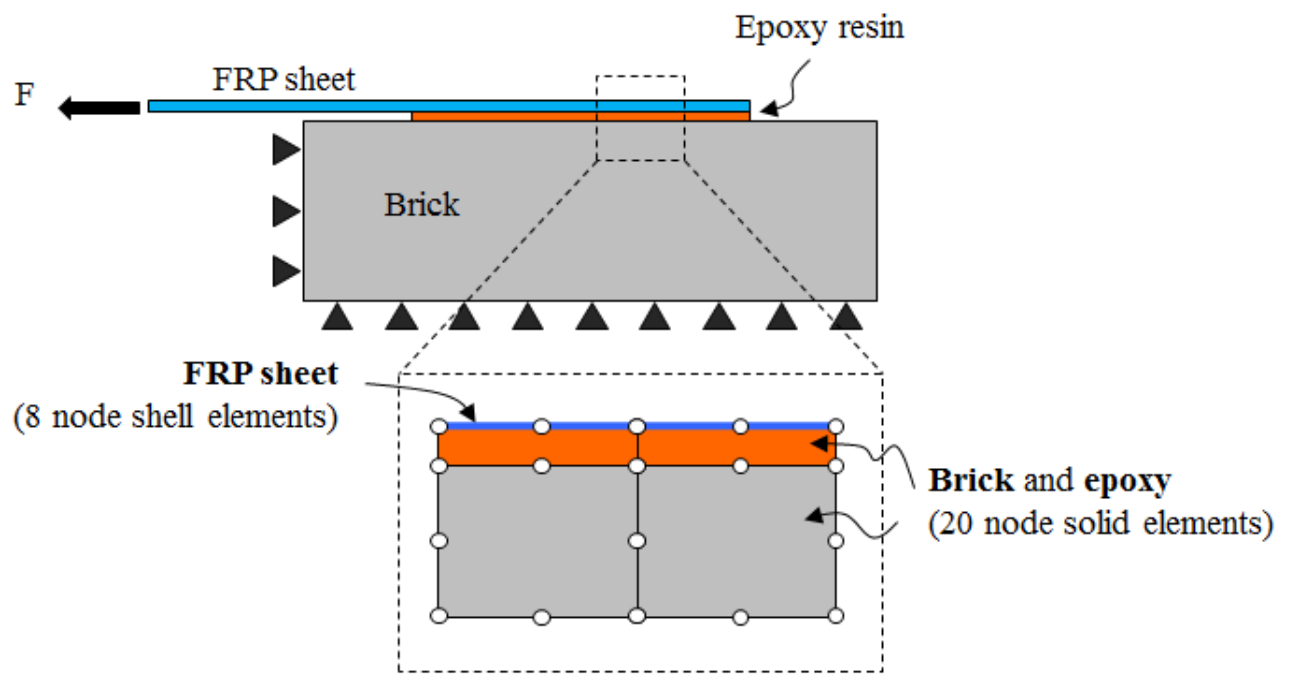

(a)

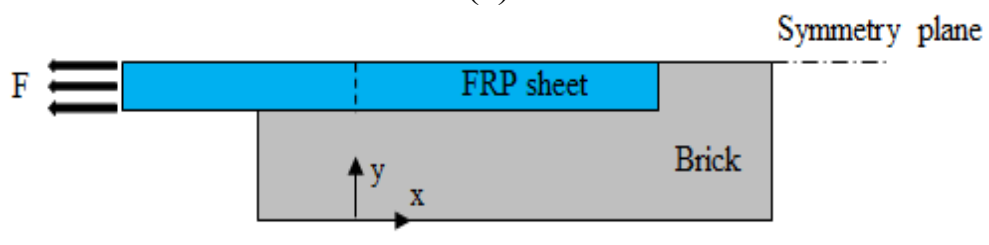

(b)

Fig.1. Adopted finite element model: (a) elevation; (b) top view (x-y plane). 


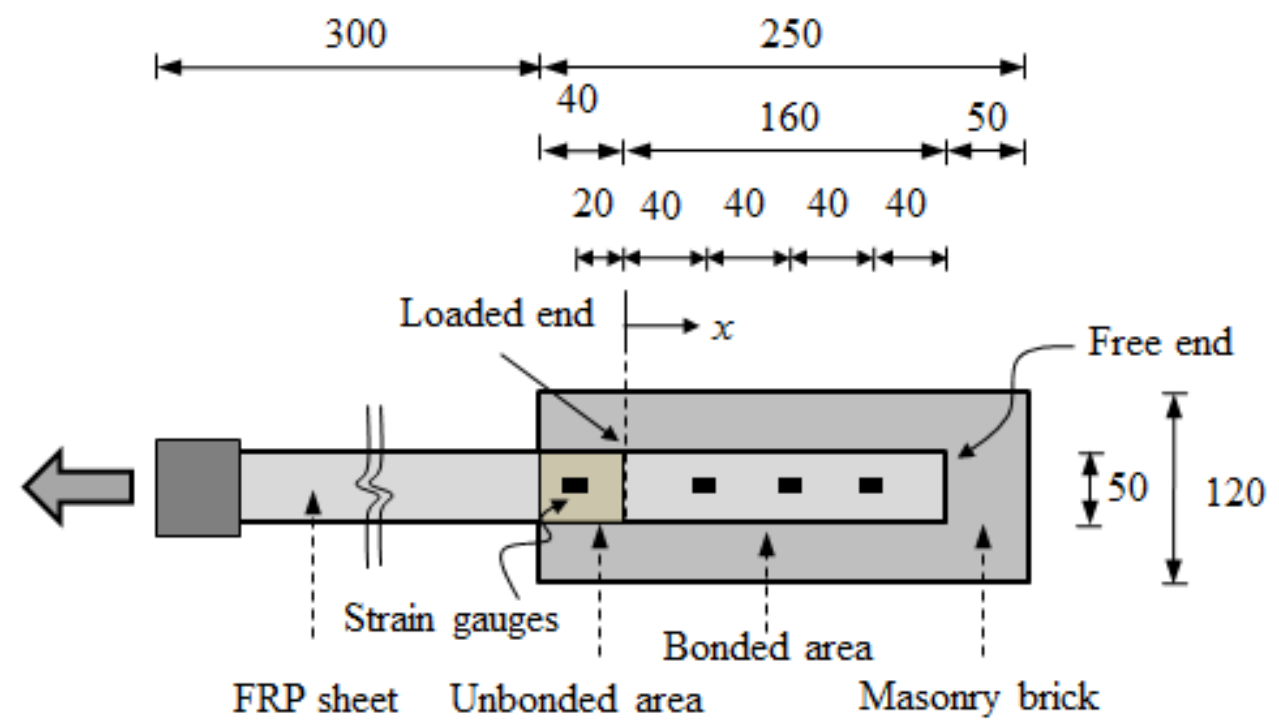

Fig.2. Geometry of the reference FRP-masonry brick specimens. 


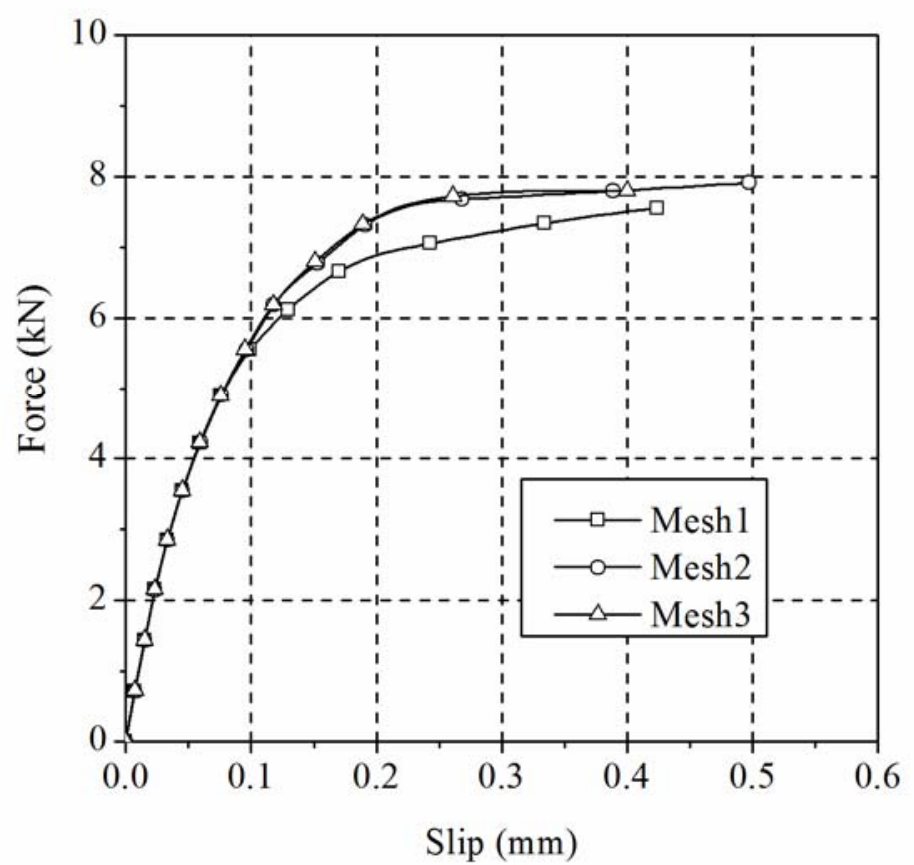

Fig.3. Force-slip curves obtained for different mesh sizes. 


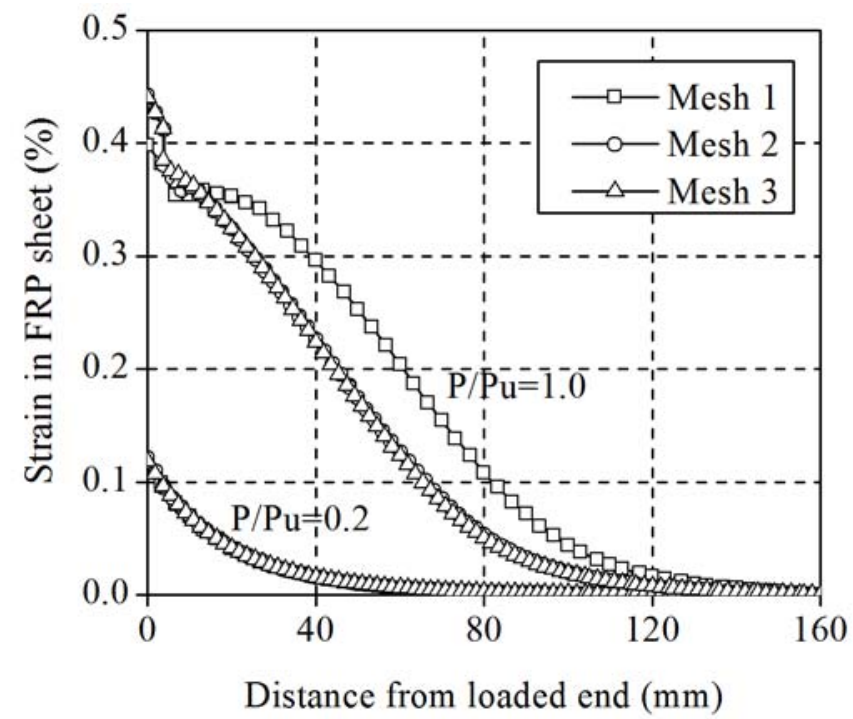

Fig.4. Effect of mesh size on strain distributions in the FRP sheet. Note that the results for all meshes coincide for $\mathrm{P} / \mathrm{Pu}=0.2$ and the results for Mesh and Mesh 3 coincide for Mesh 2 and Mesh 3. 

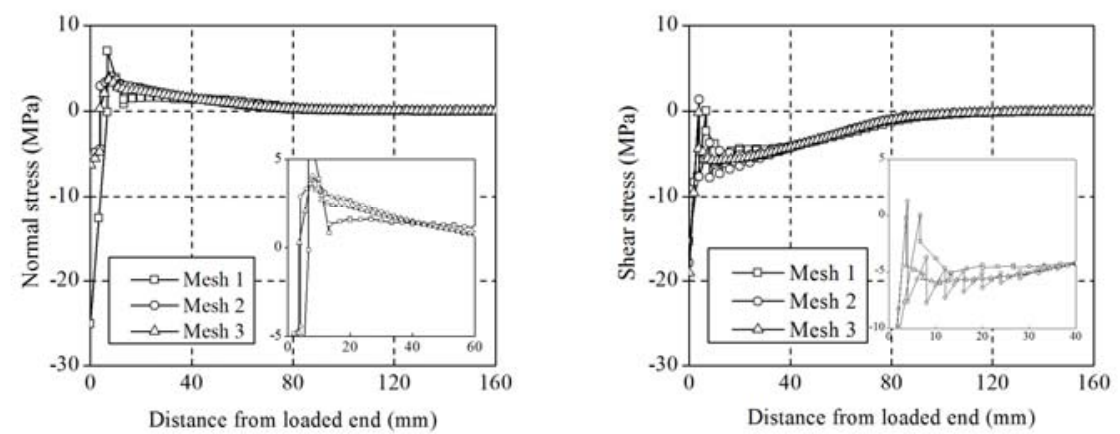

(a)
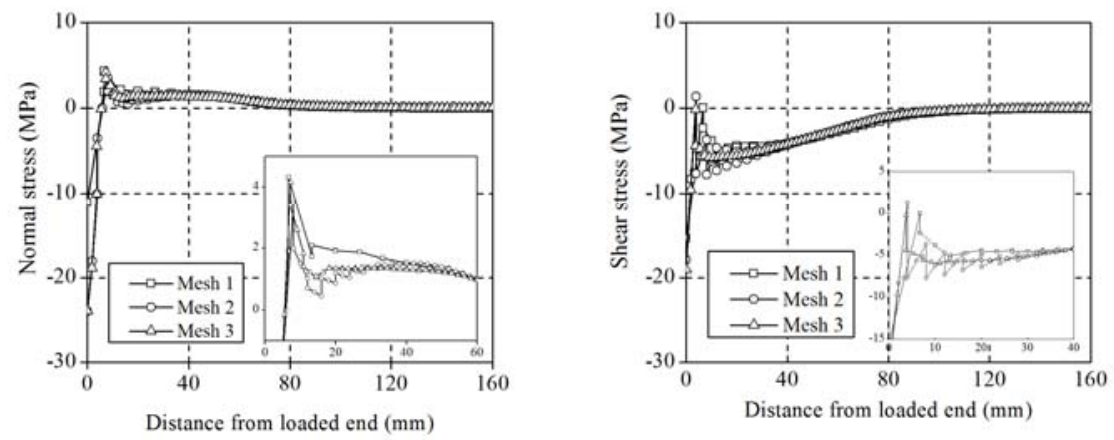

(b)

Fig.5. Effect of mesh size on stress distributions at the ultimate load level, $\mathrm{P} / \mathrm{P}_{\mathrm{u}}=1.0$ : (a) adhesive mid-section; (b) adhesive-brick interface. 


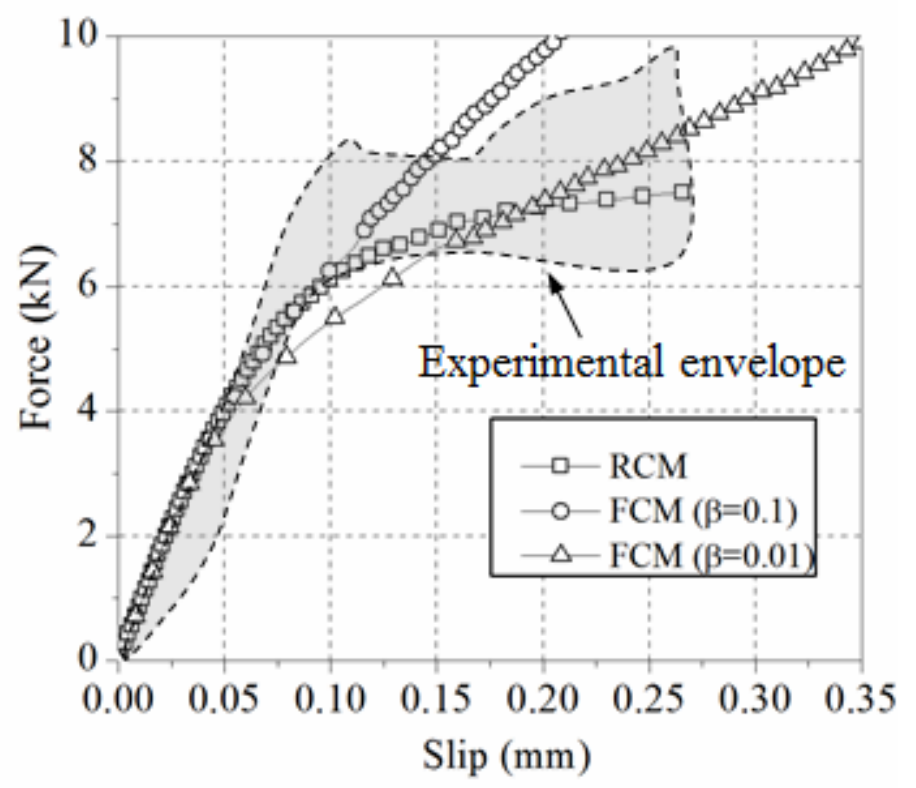

Fig.6. Force-slip curves obtained for different crack models. 


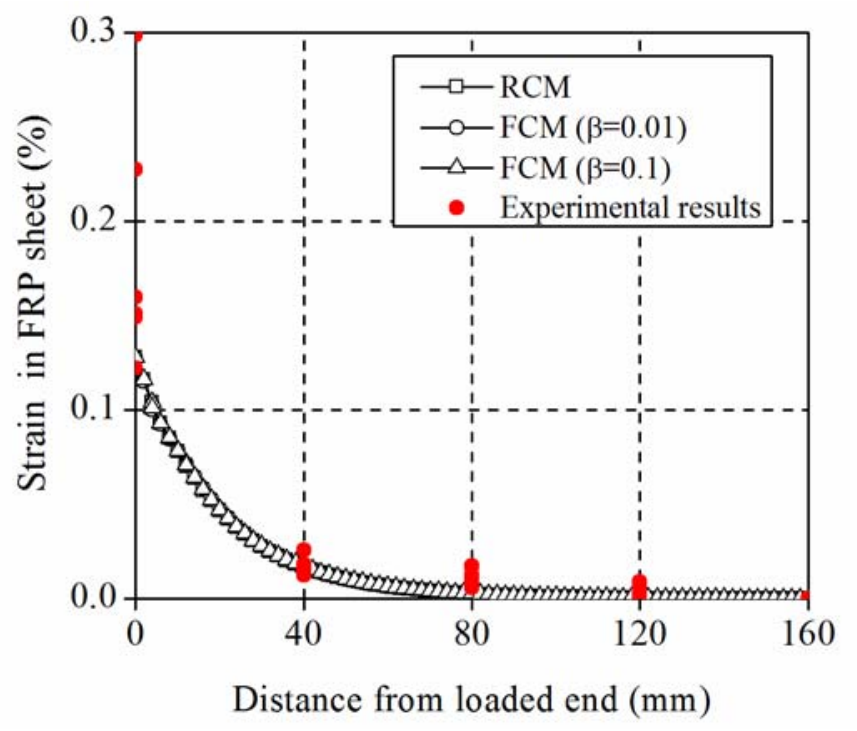

(a)

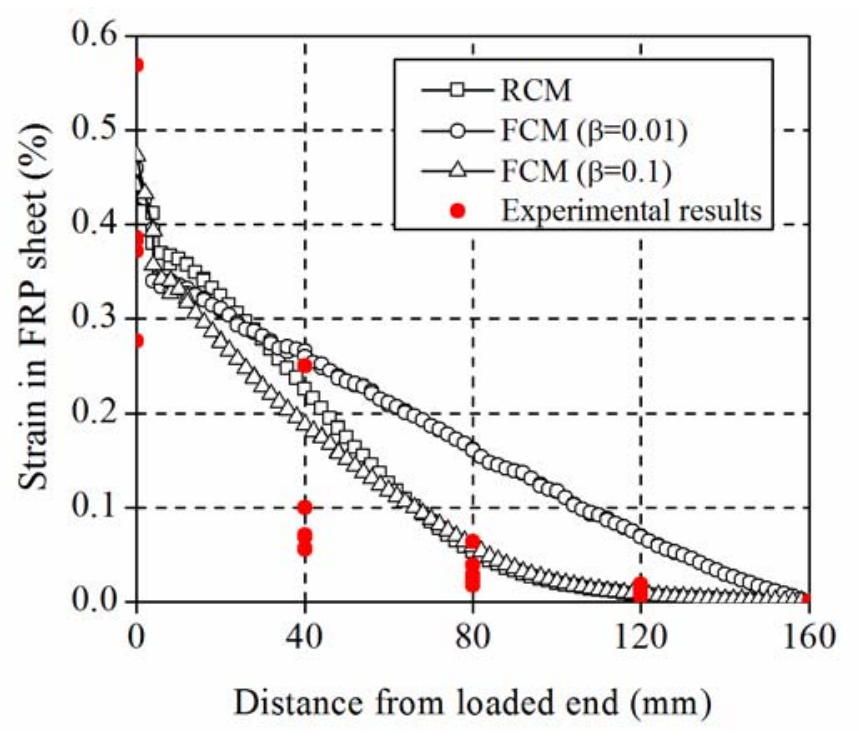

(b)

Fig.7. Strain distributions along the FRP sheet for different crack models: (a) $\mathrm{P} / \mathrm{P}_{\mathrm{u}}=0.2$;

(b) $\mathrm{P} / \mathrm{P}_{\mathrm{u}}=1.0$. 


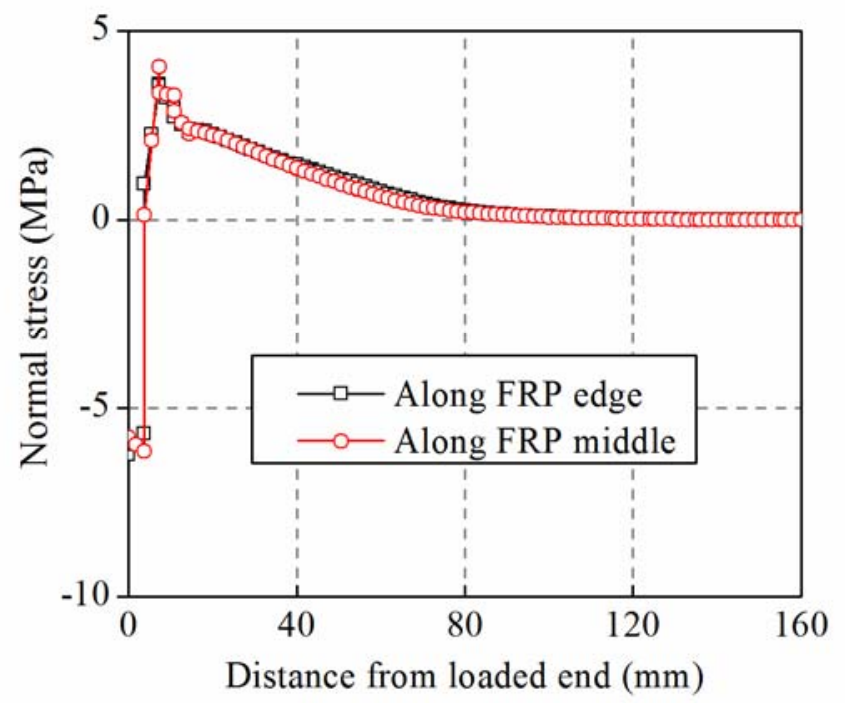

(a)

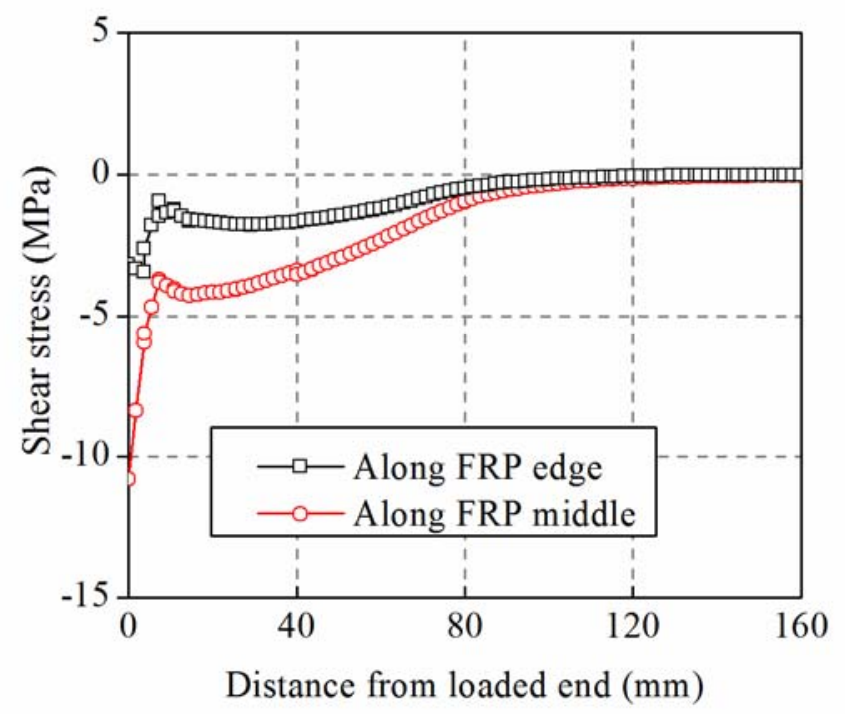

(b)

Fig.8. Stress distributions along the bonded length at mid-height-adhesive section at $\mathrm{P} / \mathrm{P}_{\mathrm{u}}=1.0$ : (a) normal stress; (b) shear stress. 


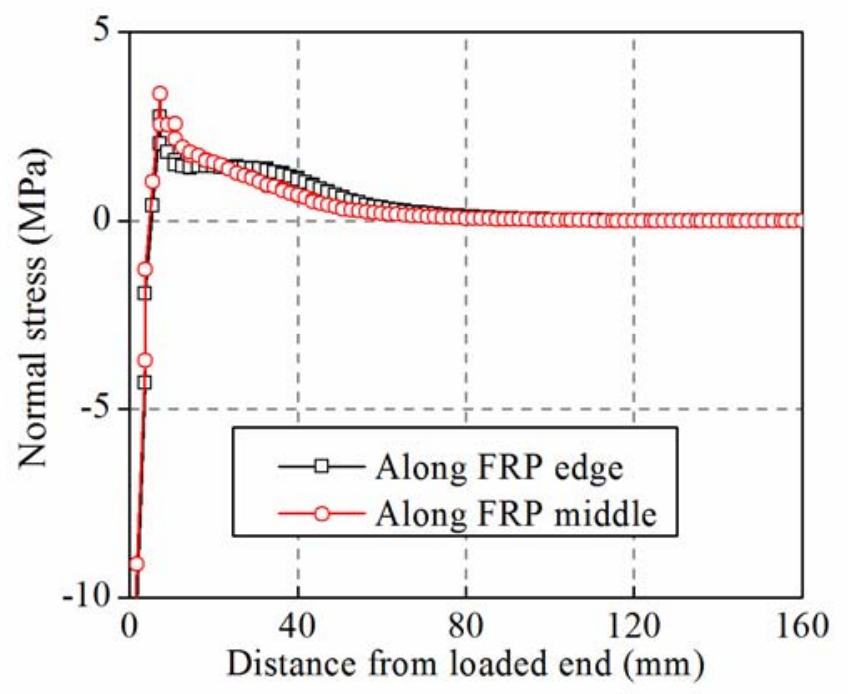

(a)

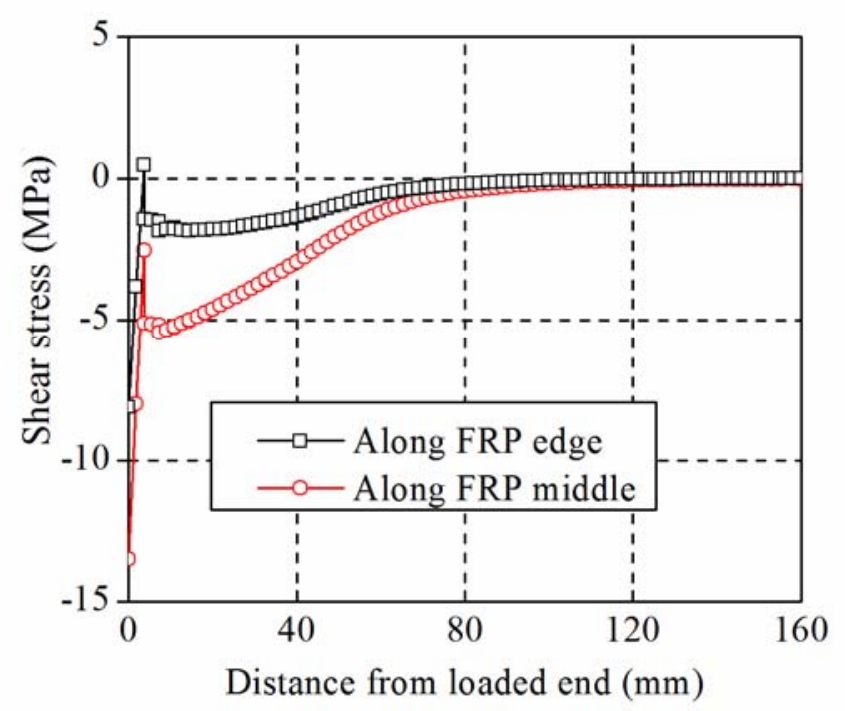

(b)

Fig.9. Stress distributions along the bonded length at brick-adhesive section at the ultimate load level, $\mathrm{P} / \mathrm{P}_{\mathrm{u}}=1.0$ : (a) normal stress; (b) shear stress. 


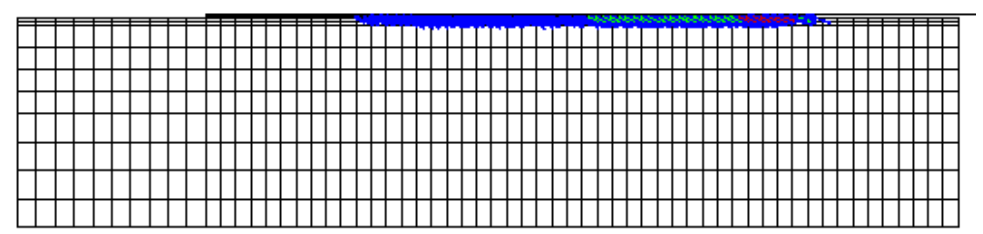

(a)

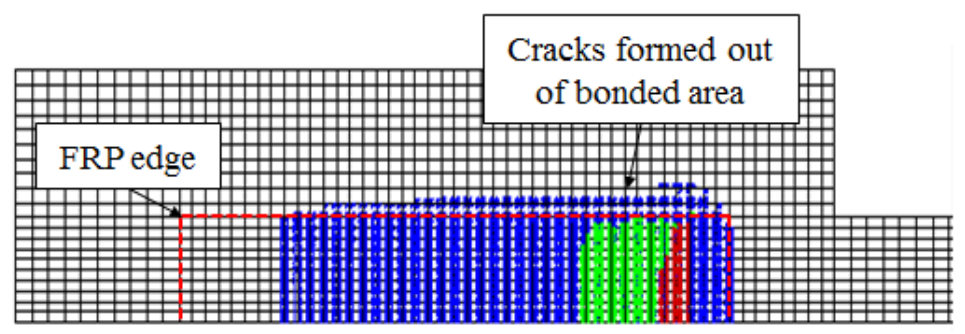

(b)

Fig.10. Numerical crack pattern of the FRP and brick specimen modeled in $3 \mathrm{D}$ at $\mathrm{P} / \mathrm{P}_{\mathrm{u}}=0.8$ : (a) side view; (b) top view. 


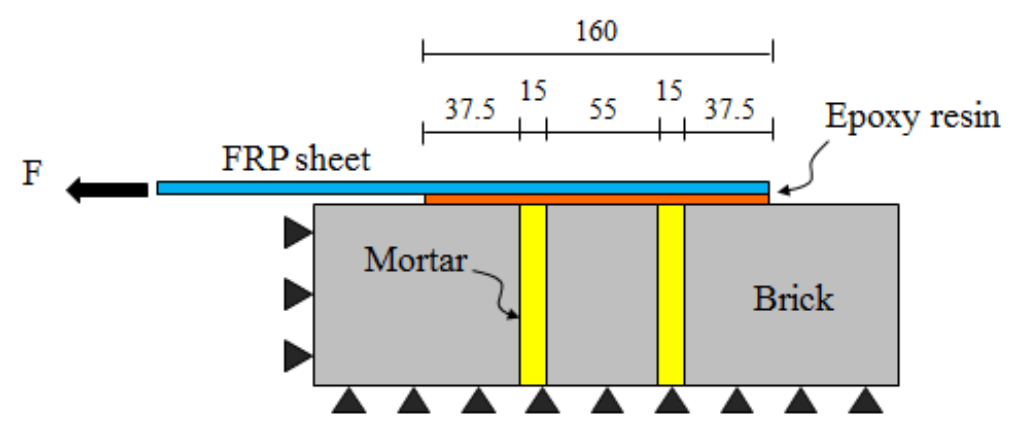

Fig.11. Adopted finite element model for FRP-strengthened masonry prism. 


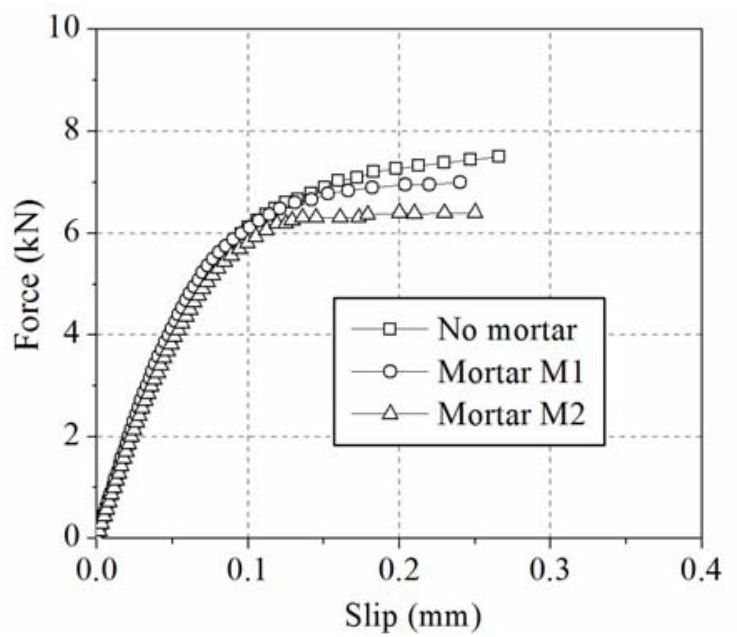

(a)

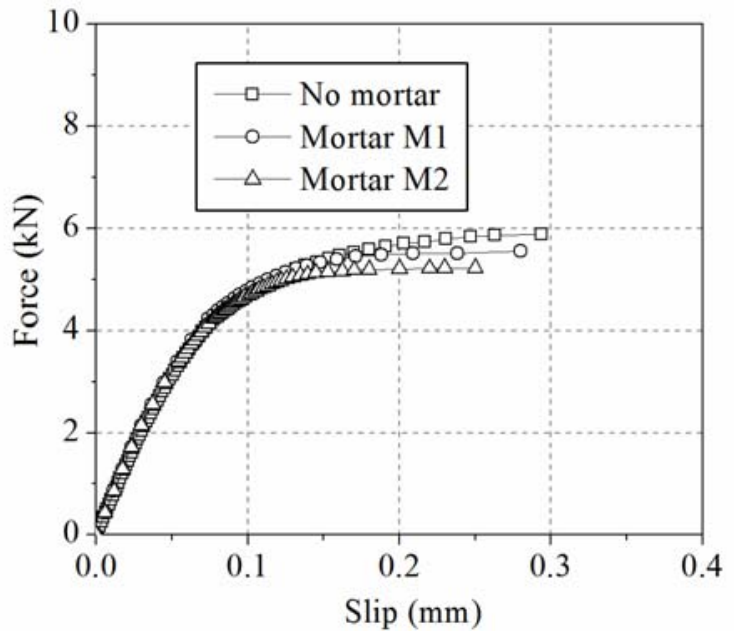

(b)

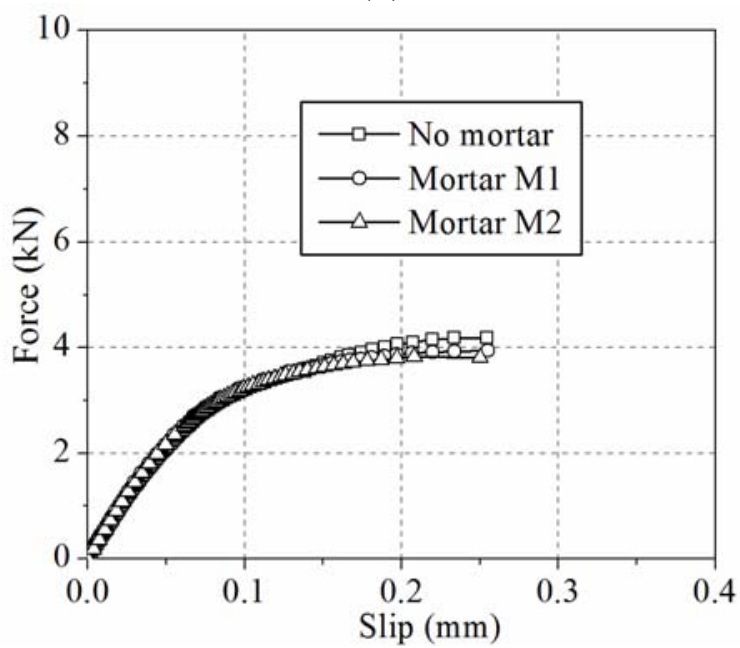

(c)

Fig.12. Force-slip curves for different mortar types and FRP axial stiffness for $r=0.42$ :

(a) $E_{\mathrm{f}} t_{\mathrm{f}}=34.3 \mathrm{kN} / \mathrm{mm}$; (b) $E_{\mathrm{f}} t_{\mathrm{f}}=20.2 \mathrm{kN} / \mathrm{mm}$; (c) $E_{\mathrm{f}} t_{\mathrm{f}}=8.4 \mathrm{kN} / \mathrm{mm}$. 


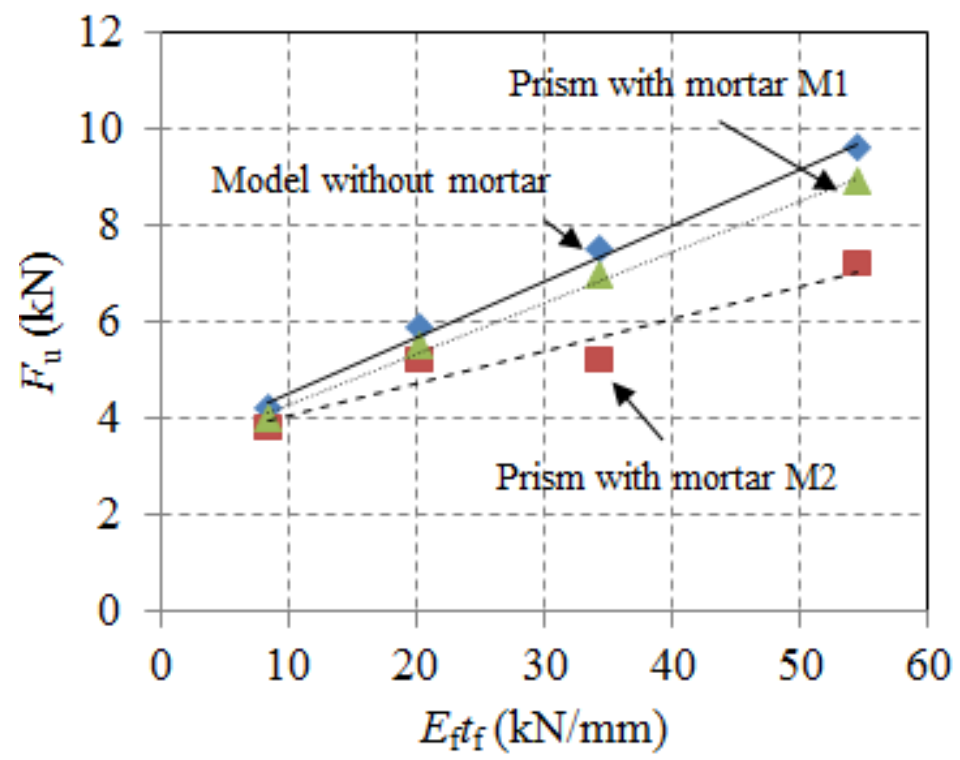

Fig.13. Variation of bond strength with FRP axial stiffness for $r=0.42$. 


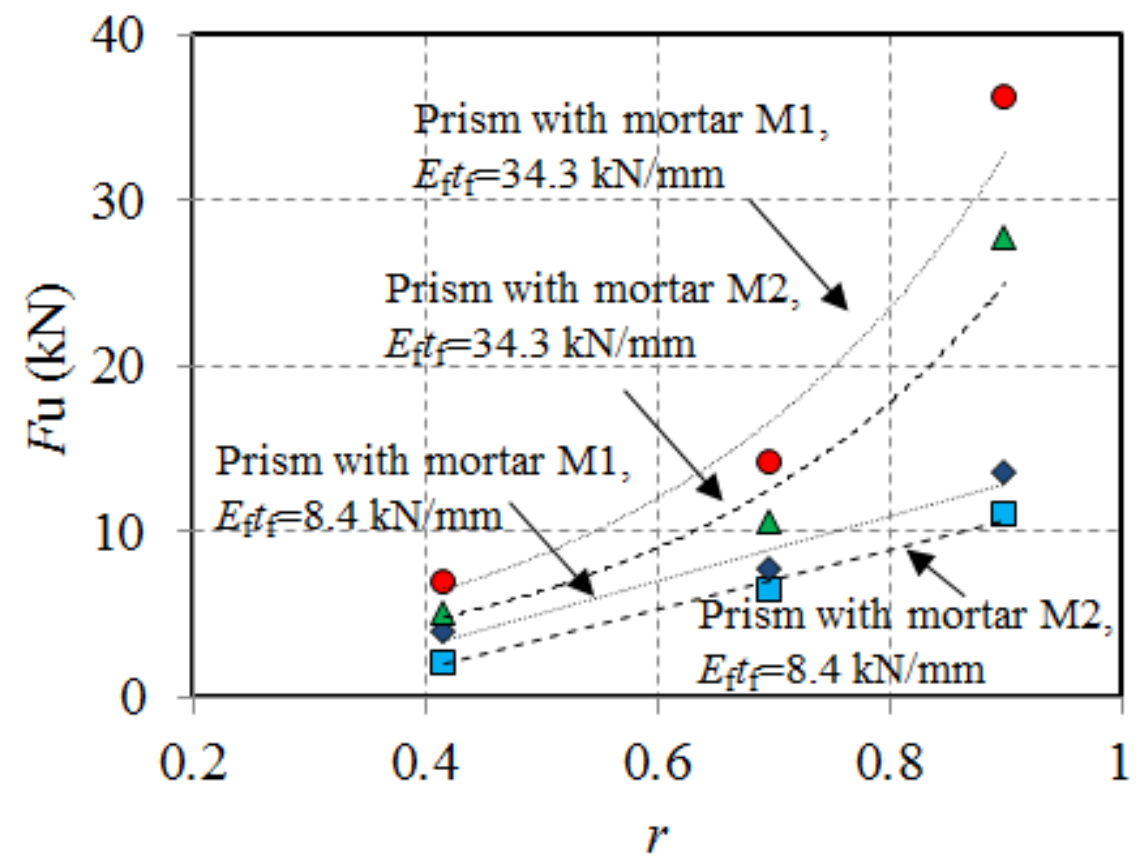

Fig.14. Effect of FRP width ratio, $r$, on the bond strength: (a) $E_{\mathrm{f}} t_{\mathrm{f}}=34.3 \mathrm{kN} / \mathrm{mm}$; (b) $E_{\mathrm{f}} t_{\mathrm{f}}$ $=8.4 \mathrm{kN} / \mathrm{mm}$. 


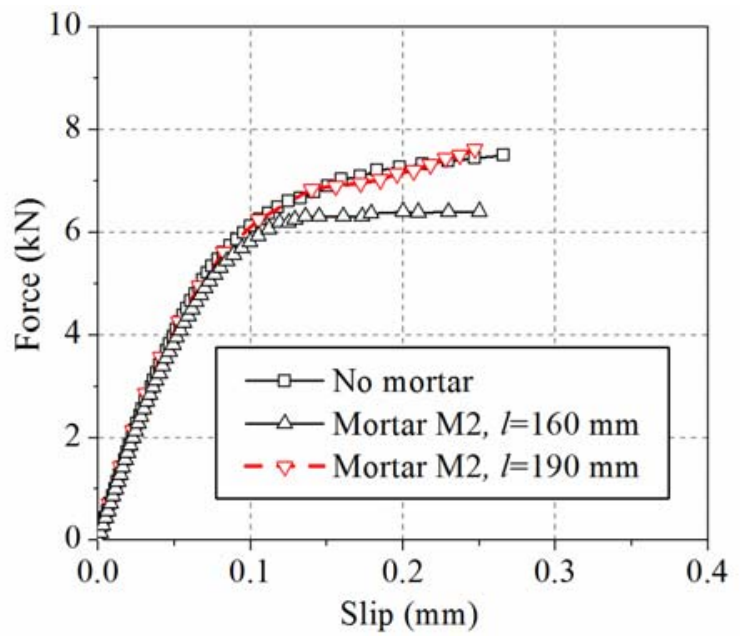

(a)

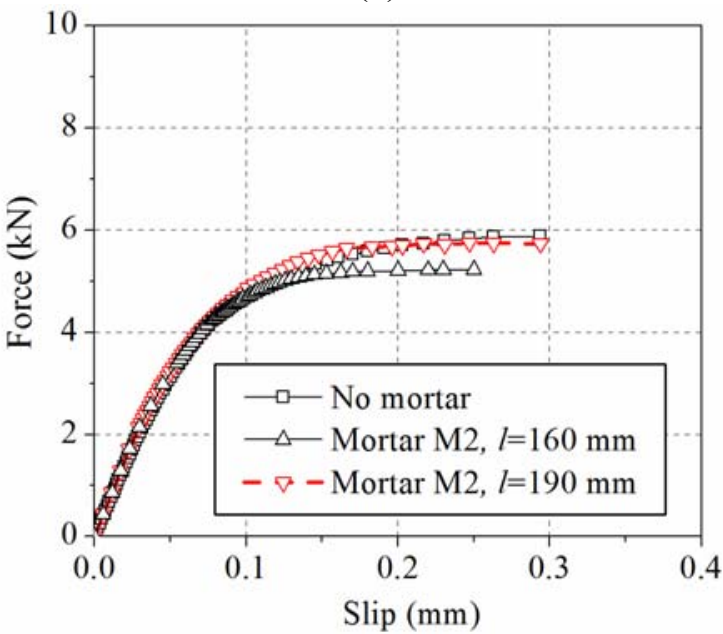

(b)

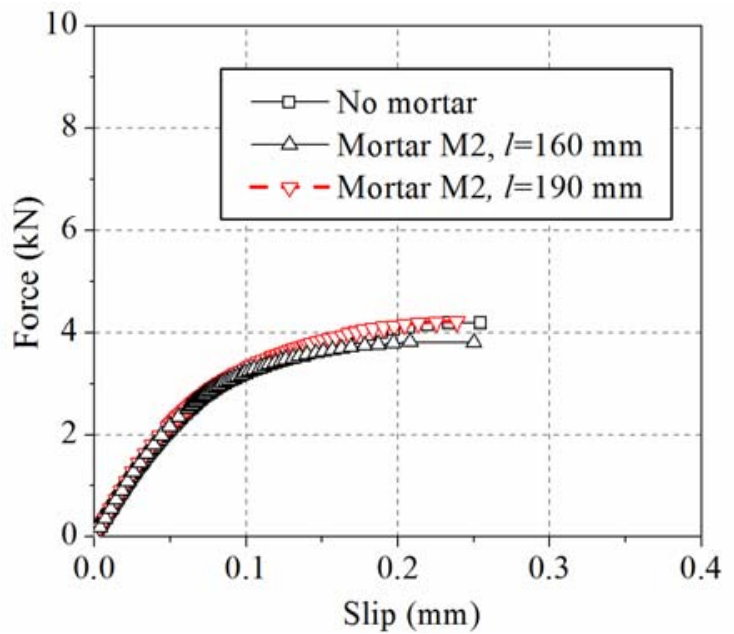

(c)

Fig.15. Effect of increase in the bond length in model M2 for $r=0.42$ : (a) $E_{\mathrm{f}} t_{\mathrm{f}}=34.3$

$\mathrm{kN} / \mathrm{mm}$; (b) $E_{\mathrm{f}} t_{\mathrm{f}}=20.2 \mathrm{kN} / \mathrm{mm}$; (c) $E_{\mathrm{f}} t_{\mathrm{f}}=8.4 \mathrm{kN} / \mathrm{mm}$. 


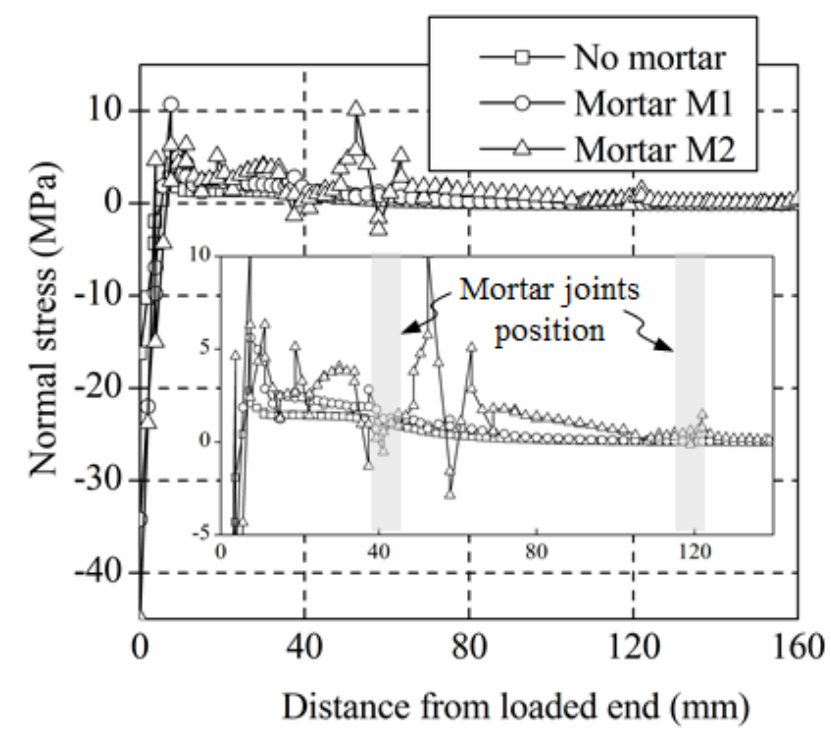

(a)

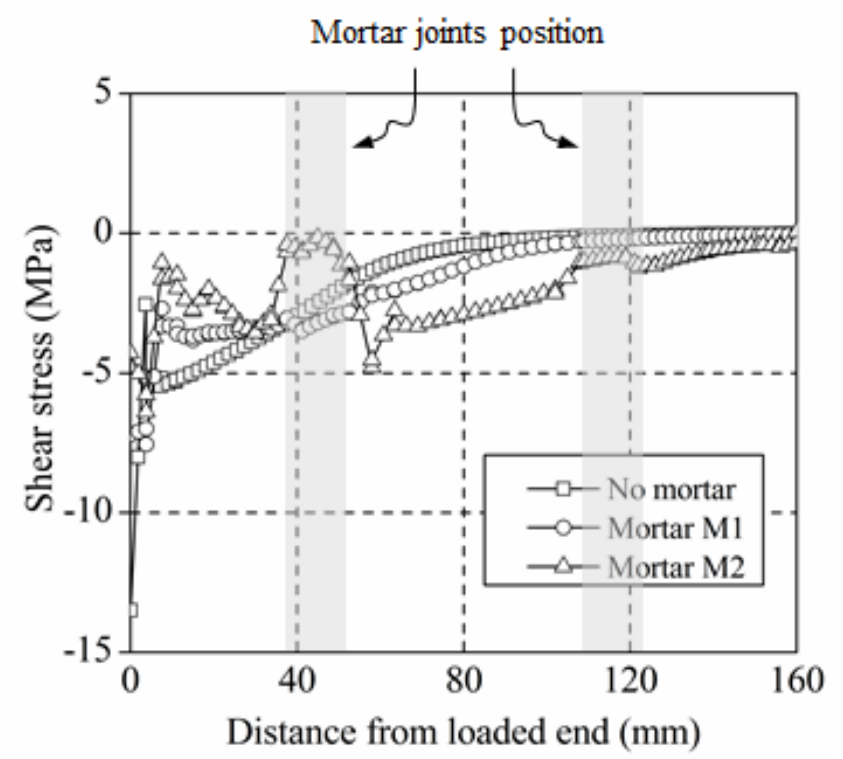

(b)

Fig.16. Stress distributions along the bonded length at $\mathrm{P} / \mathrm{P}_{\mathrm{u}}=1.0$ for $E_{\mathrm{f}} t_{\mathrm{f}}=34.3 \mathrm{kN} / \mathrm{mm}$ and $r=0.42$ : (a) normal stress; (b) shear stress. 

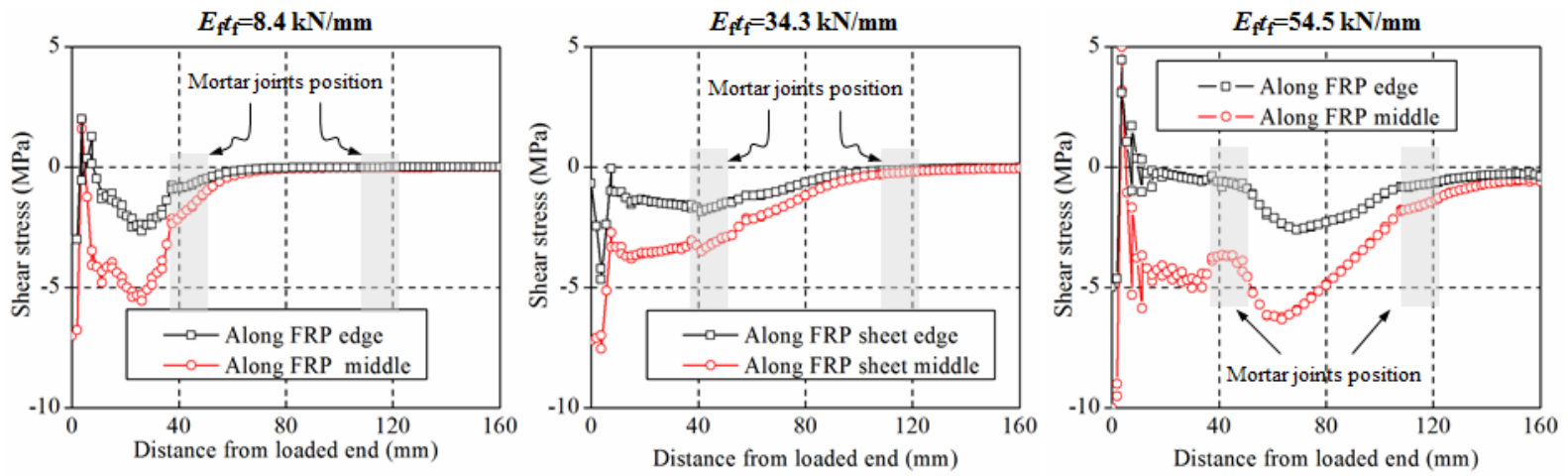

(a)
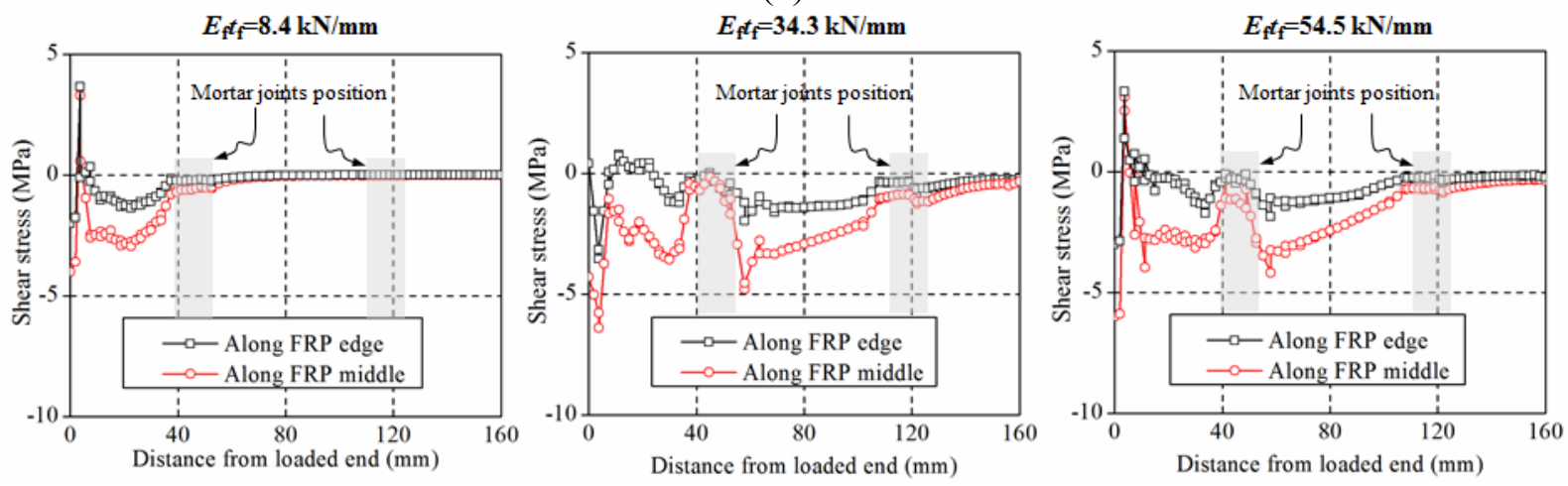

(b)

Fig.17. Shear stress distributions along the bonded length at the interface for $\mathrm{P} / \mathrm{P}_{\mathrm{u}}=1.0$ :

(a) prism with mortar M1; (b) prism with mortar M2. 


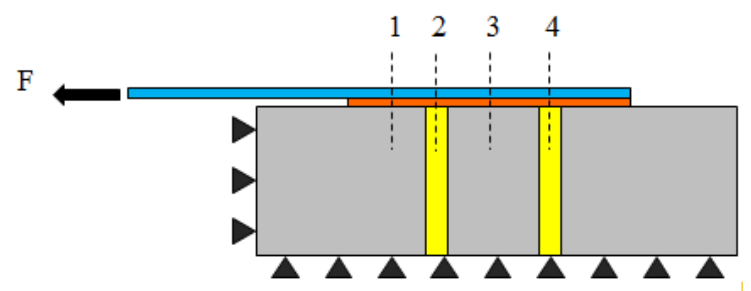

(a)

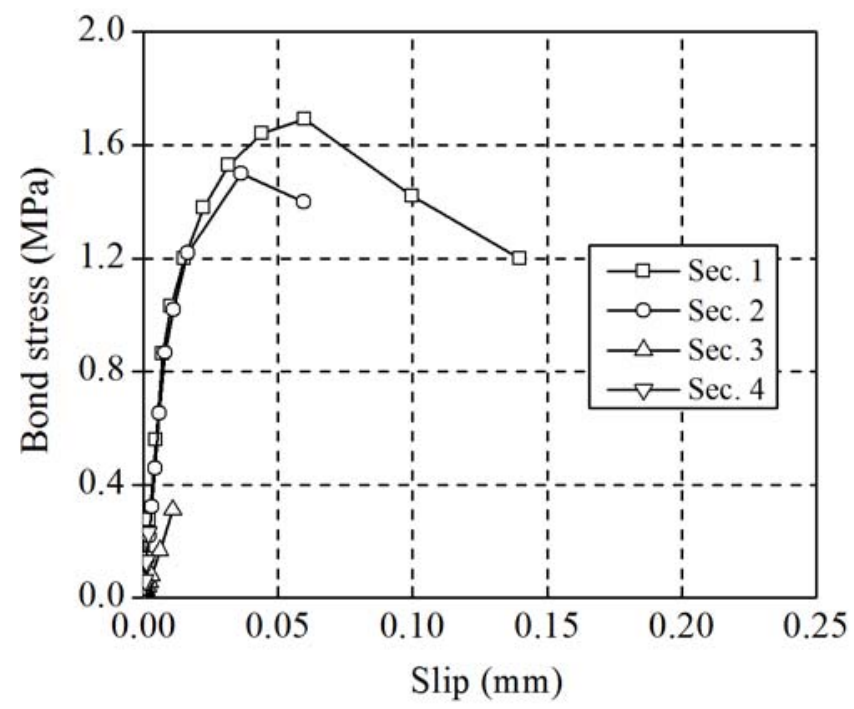

(b)

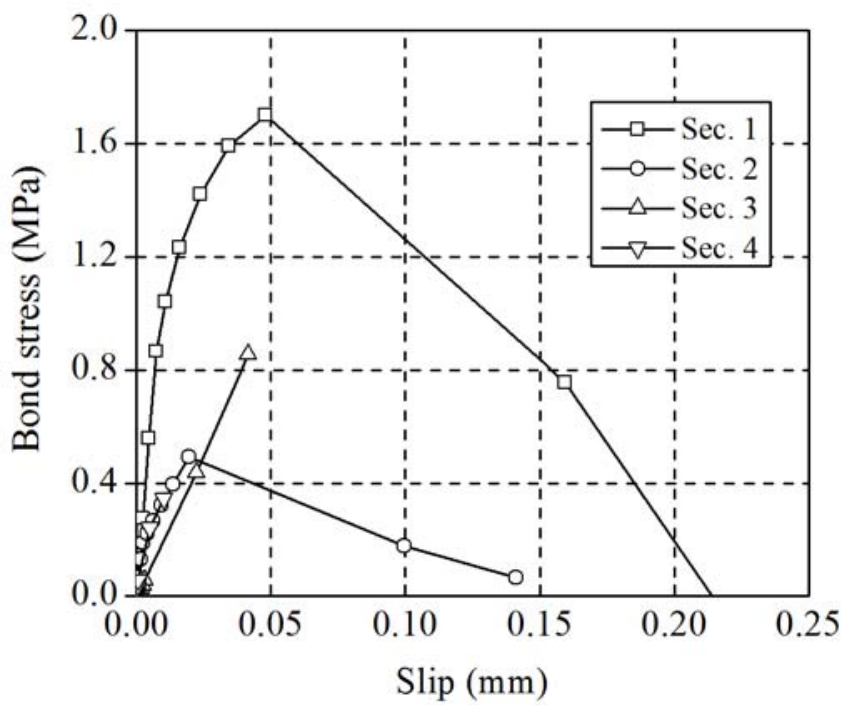

(c)

Fig.18. FE local bond-slip curves: (a) sections under investigation; (b) model with mortar M1; (c) model with mortar M2. 


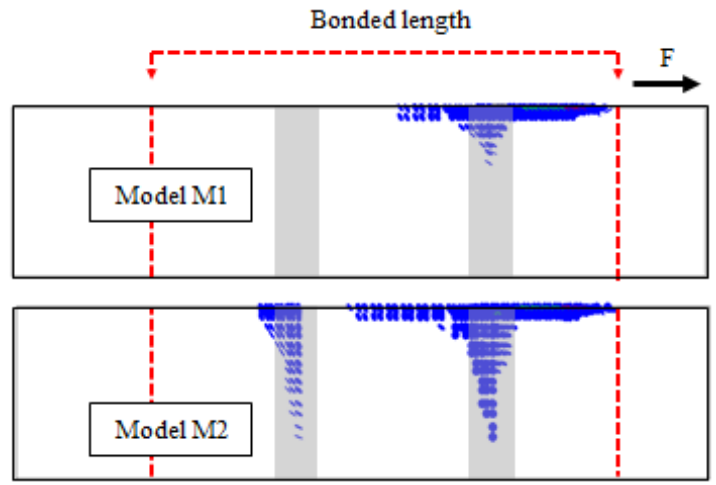

(a)

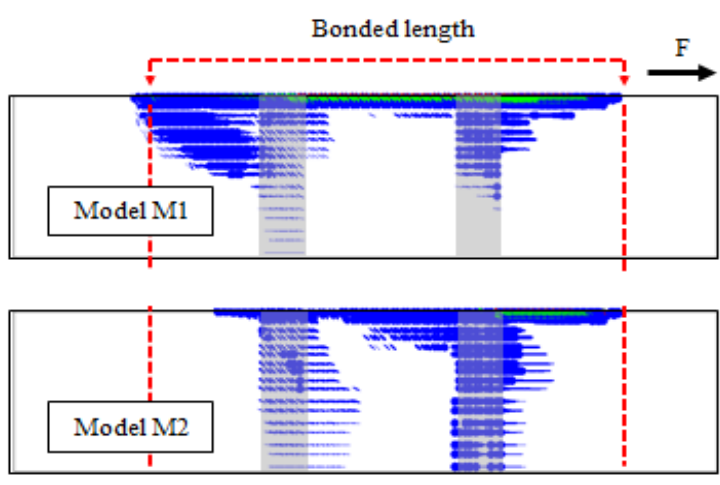

(b)

Fig.19. Crack distributions for $E_{\mathrm{f}} t_{\mathrm{f}}=34.3 \mathrm{kN} / \mathrm{mm}$ and different $r$ ratios: (a) $r=0.42$; (b) $r=0.9$. 